\title{
Effect of Salvia chorassanica Root Aqueous, Ethanolic and Hydro Alcoholic Extracts on Staphylococcus aureus, Enterococcus faecalis, Salmonella typhimurium and Escherichia coli
}

\author{
Azam Mehraban,, Mohammad Reze Edalatian Dovom,, ${ }^{1, *}$ Mohammad Hosein Haddad Khodaparast, ${ }^{1}$ \\ and Masoumeh Mehraban Sang Atash ${ }^{2}$ \\ ${ }^{1}$ Department of Food Science and Technology, Agriculture Faculty, Ferdowsi University of Mashhad, Mashhad, Iran \\ ${ }^{2}$ Food Quality and Safety Department, Food Science and Technology Research Institute, Mashhad Branch, Mashhad, Iran \\ "Corresponding author: Mohammad Reze Edalatian Dovom, Department of Food Science and Technology, Agriculture Faculty, Ferdowsi University of Mashhad, Mashhad, Iran. \\ Tel: +98-9155151170, E-mail: edalatian@um.ac.ir
}

Received 2015 November 28; Accepted 2016 October 28.

\begin{abstract}
Background: Nowadays, through the previous researches, it has become clear that Salvia has important health benefits. Salvia chorassanica is one of the valuable native Iranian species which only grows in Khorasan province, Iran.

Objectives: The aim of this study is to evaluate the antimicrobial effect of Salvia chorassanica root aqueous, ethanolic and hydro alcoholic extracts on Staphylococcus aureus, Enterococcus faecalis, Salmonella typhimurium and Escherichia coli.

Methods: In this experimental study, maceration method was used to prepare extracts. Study setup was conducted in March 2014.The duration of study setup took for two months. The micro dilution method by ELISA was used to determine the minimum inhibitory concentration (MIC) and minimum bactericidal concentration (MBC) of aqueous, ethanolic and hydro alcoholic extracts of root of Salvia chorassanica against Staphylococcus aureus, Enterococcus faecalis, Salmonella typhimurium and Escherichia coli. The antibacterial effect also was evaluated using agar diffusion method. The inhibition zones of growth against the extracts were measured in comparison to standards antibiotics. Chloramphenicol as positive control on Enterococcus faecalis, Tetracycline on Staphylococcus aureus, Gentamicin on Escherichia coli and Neomycin on Salmonella typhimurium. The data were analyzed using one way analysis of variance (ANOVA) with SPSS version 16.

Results: The highest inhibition zone in diffusion method was related to ethanolic extract of Salvia chorassanica root against Grampositive bacteria, Staphylococcus aureus and Enterococcus faecalis. The calculated MIC in aqueous and ethanolic extracts of root for Staphylococcus aureus was 240 and $120 \mathrm{mg} / \mathrm{mL}$, for Enterococcus faecalis was 120 and $60 \mathrm{mg} / \mathrm{mL}$ respectively, and for Escherichia coli and Salmonella typhimurium was equal to $240 \mathrm{mg} / \mathrm{mL}$. The amount in hydro alcoholic extracts for Gram-positive bacteria was $60 \mathrm{mg} / \mathrm{mL}$ and for Gram-negative bacteria was $120 \mathrm{mg} / \mathrm{mL}$. The extract of Salvia chorassanica root was showed acceptable antimicrobial effect against studied bacteria.

Conclusions: The results of the disk agar diffusion and micro dilution showed the highest inhibitory effect on the tested bacteria was related to ethanolic and hydro alcoholic extracts of root Salvia chorassanica. It was also observed that the Gram-positive bacteria compared to the Gram- negative bacteria, have greater sensitivity against different extracts of Salvia chorassanica.
\end{abstract}

Keywords: Antibacterial Agent, Dilution Techniques, Disk Diffusion Antimicrobial Tests, Salvia

\section{Background}

Plant oils and extracts have been used for a wide variety of purposes for many thousands of years. In particular, the antimicrobial activity of plant oils and extracts has formed the basis of many applications, including raw and processed food preservation, pharmaceuticals, alternative medicine and natural therapies [1]. They have variable mixtures of principally terpenoids, specifically monoterpenes (C10) and sesquiterpenes (C15) although diterpenes
(C20) may also be present, and a variety of low molecular weight aliphatic hydrocarbons (linear, ramified, saturated and unsaturated), acids, alcohols, aldehydes, acyclic esters or lactones and exceptionally nitrogen-and sulphurcontaining compounds, coumarins and homologues of phenylpropanoids. Terpenes are amongst the chemicals responsible for the medicinal, culinary and fragrant uses of aromatic and medicinal plants. Most terpenes are derived from the condensation of branched five-carbon isoprene units and are categorized according to the number 
of these units present in the carbon skeleton [2].

Even though pharmacological industries have produced a number of new antibiotics in the last three decades, resistance to these drugs by microorganisms has increased. In general, bacteria have the genetic ability to transmit and acquire resistance to drugs, which are utilized as therapeutic agents [3]. Due to the increase of resistance to antibiotics, there is a pressing need to develop new and innovative antimicrobial agents. Among the potential sources of new agents, plants have long been investigated. Because, they contain many bioactive compounds that can be of interest in therapeutic [4].

The genus salvia (Lamiaceae) with about 900 different species, divided into five subgenera (Sclarea, Audibertia, Jungia, Leonia and salvia), present in diverse areas as the Mediterranean, Central Asia, Pacific Islands, tropical Africa and America of which 17 species are endemic to Iran. The genus salvia has widely used in traditional folk medicine. Previous phytochemical investigations revealed the presence of phenolic acid and polyphenols, flavonoide glycosides, anthocyanins, diterpenes and sesquiterpenes in the several salvia species. Different parts of the plant especially root are a rich source of different phytochemicals including terpenoids, polyphenols. Salvia chorassanica is one of the most valuable species of the salvia genus. This plant is native to Iran and grows only in Khorasan Razavi province $[5,6]$.

\section{Objectives}

The objective of this study was to evaluate the antibacterial and inhibition potential of aqueous, ethanolic and hydro alcoholic extracts of Salvia chorassanica root against Staphylococcus aureus ATCC 6538, Enterococcus faecalis ATCC 21299, Salmonella typhimurium ATCC 14028 and Escherichia coli ATCC 25922.

\section{Methods}

\subsection{Preparation Plant}

Salvia chorassanica was collected from the Zoshk heights area of Mashhad, in Khorasan Razavi province, in March 2014 and taxonomic identification was performed by the faculty of science herbarium, Ferdowsi university of Mashhad, Iran.

\subsection{Extract Preparation}

In this experimental study, Maceration method was used to prepare extracts. The amount 50 gram of root of Salvia chorassanica powder was added to $250 \mathrm{~mL}$ ethanol $96 \%$, water or mixture of water and ethanol (with ratio 20 :
80). Erlenmeyer flask containing the mixture was placed at laboratory temperature on a magnetic stirrer for 72 hours. Upper liquid was centrifuged in $3000 \mathrm{rpm}$ for 10 minutes and was filtered using paper filters $(0.45 \mu)$. In continuation rotary was used to remove the solvent. In the end, in order to avoid the effects of light and heat the extracts were covered with aluminum foil and stored at refrigerator temperatures. All experiments were repeated 3 times $[7,8]$.

\subsection{Preparation of Microbial Suspension}

To prepare the microbial suspensions, 24 hours before experiments, microorganisms were inoculated from storage medium on Muller Hinton agar medium. After the growth of bacterial strain, the cultures were washed by Ringer solution and microbial suspensions were prepared. Then the turbidity was measured by spectrophotometer at $625 \mathrm{~nm}$ wavelength and it was diluted by ringer solution until the solution turbidity equalizes with 0.5 McFarland standard solutions [9].

\subsection{The Disk Diffusion Method}

The antimicrobial effects of extracts were assayed by disk agar diffusion methods. In this method, first one loop of standard culture of each strain was cultured on agar, and then it was spread on the surface of agar by sterile glass spreader. The aqueous extract was diluted by sterile distilled water and ethanolic and hydro alcoholic extracts were diluted by $5 \%$ dimethyl sulfoxide, and were passed throughout the $0.45 \mu$ filter. Finally the discs were kept over the agar plates using sterile forceps at 240, 480 and $960 \mathrm{mg} / \mathrm{mL}$ concentrations. After placing the plate at $37^{\circ} \mathrm{C}$ for 24 hours, the antibacterial activity was observed as inhibition zone on Petri plates. Size of the inhibition zone was measured in millimeters using a metric ruler [10]. The inhibition zones of growth against the extracts were measured in comparison to standards antibiotics. Chloramphenicol as positive control on Enterococcus faecalis, tetracycline on Staphylococcus aureus, gentamicin on Escherichia coli and neomycin on Salmonella typhimurium.

\subsection{Minimum Inhibitory Concentration (MIC)}

The inocula of bacteria were prepared from 24 hours broth cultures and suspensions were adjusted to $0.5 \mathrm{Mc}$ Farland standard turbidity. The aqueous extract of root of Salvia chorassanica dissolved in sterile distilled water and ethanolic and hydro alcoholic extracts dissolved in $0.5 \%$ dimethylsulfoxide. These were first diluted to the highest concentration $(960 \mathrm{mg} / \mathrm{mL})$, and then serial twofold dilutions were made. The 96 -well plates were prepared by dispensing into each well $95 \mu \mathrm{L}$ of nutrient broth and $5 \mu \mathrm{L}$ of the inoculums (Except well No. 11). A $100 \mu \mathrm{L}$ aliquot from 
Salvia chorassanica root extracts initially prepared at the concentration of $960 \mathrm{mg} / \mathrm{mL}$ was added into the first well. Then, $100 \mu \mathrm{L}$ from their serial dilutions was transferred into ten consecutive wells. Finally $100 \mu$ L from well No. 11 was discarded. This well was negative control and well No. 12 was positive control (without extract). The final volume in each well was $200 \mu \mathrm{L}$. Initial turbidity of the wells was read at a wavelength of $630 \mathrm{~nm}$ using the ELISA reader after 7 seconds. After incubation of the plate at $37^{\circ} \mathrm{C}$ for 24 hours the readings absorbencies were compared. The lowest concentration that inhibits the growth of bacteria was considered as minimum inhibitory concentration $[11,12]$.

\subsection{Minimum Bactericidal Concentration (MBC)}

To determine MBC, from each well where no turbidity was observed, $10 \mu \mathrm{L}$ were transferred on Mueller Hinton agar medium. The plates were incubated for 24 hours at $37^{\circ} \mathrm{C}$. After the incubation results were evaluated and the concentration with no growth of bacteria was considered as minimum bactericidal concentration [13].

\subsection{Statistical Analysis}

The data were analyzed using one way analysis of variance (ANOVA) with SPSS version 16. The Duncan's test was used to compare the means $(\mathrm{P}<0.05)$.The graphs were plotted with Slide write and experimental data were presented as Mean (or average) \pm SD.

\section{Results}

The results of the antimicrobial effects of aqueous, ethanolic and hydro alcoholic extracts of Salvia chorassanica root by the agar diffusion method were presented in Table 1.

The results of MIC and MBC of aqueous, ethanolic and hydro alcoholic extract of Salvia chorassanica root were presented in Tables 2 and 3.

As presented in Table 1, the maximum inhibition zone was related to ethanolic extract on Enterococcus faecalis. The aqueous and ethanolic extracts had no antibacterial activity against Salmonella typhimurium, Escherichia coli. The results also showed that the hydro alcoholic extract compared to ethanolic extract had more antibacterial activity and ethanolic extract compared to aqueous was more effective.

According to the results of inhibition zone of common therapeutic antibiotics it can be seen that the investigated extracts against Staphylococcus aureus and Escherichia coli did not exhibited wider inhibition zone than those of corresponding antibiotics.
The drawn graphs by slide write software to determine the MIC range of root extracts for tested bacteria were presented in Figures 1 - 3. The graphs were determined the range of the antibacterial effect of extracts, was the confluence of the turbidity plot of treatment (microorganisms, extracts and culture) with turbidity plot of the blank (extract and culture). The range of MIC is the area that the growth graph of bacteria was being below control graph, to the point of confluence of two graphs.

Evaluation of results showed that the inhibitory effect of ethanolic and hydro alcoholic extracts of Salvia chorassanica root on tested bacteria was effective compared to aqueous extract at the same concentrations and this more inhibitory effect is proportional to more percentage of extraction of ethanolic and hydro alcoholic extracts. In comparison with the percentage of the dry weight of the aqueous extract and other extracts can be found that with decreasing of dry weight of aqueous extract the amount of extraction of antimicrobial compounds also was reduced.

\section{Discussion}

Our results of the disk agar diffusion and micro dilution showed the highest inhibitory effect on the tested bacteria was related to ethanolic and hydro alcoholic extracts of root Salvia chorassanica. It was also observed that the Gram-positive bacteria compared to the Gram-negative bacteria, have greater sensitivity against different extracts of Salvia chorassanica. New antibiotics were produced by pharmacological industries in the last three decades. However, these antibiotics have failed to discourage the growth of many bacteria that have genetic ability to transmit and acquire resistance to drugs. Medicinal plants may have the ability to treat bacterial resistance to many types of antibiotics, because of their safety and low cost as well as their impact on a large number of microbes $[14,15]$.

Plant based antimicrobial compounds have enormous therapeutically potential as they can prepared the purpose, without any side effects that are often associated with synthetic antimicrobials. Plants are used as important source for traditional medications [16].

According to our findings in this research, aqueous extract of this plant had antimicrobial activity only on Enterococcus faecalis. These results showed that aqueous extract had the inhibitory effect on Enterococcus faecalis merely in 480 and $960 \mathrm{mg} / \mathrm{mL}$ concentrations. Similarly, Heidari-Sureshjani et al. [17] found aqueous extract of S. bachtiarica at 60 and $80 \mathrm{mg} / \mathrm{mL}$ had the inhibitory effect on Enterobacter aerogenes, however, 20 and $40 \mathrm{mg} / \mathrm{mL}$ have no significant antimicrobial effect on E. aerogenes. These findings may be due to the choice of extraction 
Table 1. Average Diameter (mm) of Microbial Free Zone Area of Aqueous, Ethanolic and Hydro Alcoholic Extracts of Salvia chorassanica Root Extract on Staphylococcus aureus, Enterococcus faecalis, Salmonella typhimurium and Escherichia coli (Disk Agar Diffusion Method) ${ }^{\mathrm{a}, \mathrm{b}}$

\begin{tabular}{|c|c|c|c|c|}
\hline \multirow[t]{2}{*}{ Type of Extract } & \multirow[t]{2}{*}{ Microorganism } & \multicolumn{3}{|c|}{ Concentration of Salvia chorassanica Root Extracts, mg/mL } \\
\hline & & 240 & 480 & 960 \\
\hline \multirow{3}{*}{ Aqueous } & Staphylococcus aureus & $0^{\mathrm{E}}$ & $0^{\mathrm{E}}$ & $0^{\mathrm{E}}$ \\
\hline & Salmonella typhimurium & $0^{\mathrm{C}}$ & $0^{\mathrm{C}}$ & $0^{\mathrm{C}}$ \\
\hline & Escherichia coli & $0^{\mathrm{E}}$ & $0^{\mathrm{E}}$ & $0^{\mathrm{E}}$ \\
\hline \multirow{3}{*}{ Ethanolic } & Enterococcus faecalis & $14.32 \pm 0.45^{\mathrm{C}}$ & $15.14 \pm 0.56^{\mathrm{B}}$ & $17.61 \pm 0.25^{\mathrm{A}}$ \\
\hline & Salmonella typhimurium & $0^{\mathrm{C}}$ & $0^{\mathrm{C}}$ & $0^{\mathrm{C}}$ \\
\hline & Escherichia coli & $0^{\mathrm{E}}$ & $0^{\mathrm{E}}$ & $0^{\mathrm{E}}$ \\
\hline \multirow{3}{*}{ Hydrialcoholic } & Staphylococcus aureus & $0^{\mathrm{E}}$ & $9.12 \pm 1.26^{\mathrm{B}}$ & $11.75 \pm 1.13^{\mathrm{C}}$ \\
\hline & Enterococcus faecalis & $12.52 \pm 0.17^{\mathrm{F}}$ & $13.15 \pm 0.27^{\mathrm{E}}$ & $15.44 \pm 0.56^{\mathrm{D}}$ \\
\hline & Escherichia coli & $0^{\mathrm{E}}$ & $8.12 \pm 0.43^{\mathrm{E}}$ & $10.48 \pm 0.34^{\mathrm{C}}$ \\
\hline
\end{tabular}

${ }^{a}$ Dissimilar capital letters in a row indicate significant differences $(\mathrm{P}<0.05)$ of the antimicrobial effect of different concentrations.

${ }^{\mathrm{b}}$ Similar capital letters in a row indicate the lack of significant differences $(\mathrm{P}<0.05)$ of the antimicrobial effect of different concentrations.
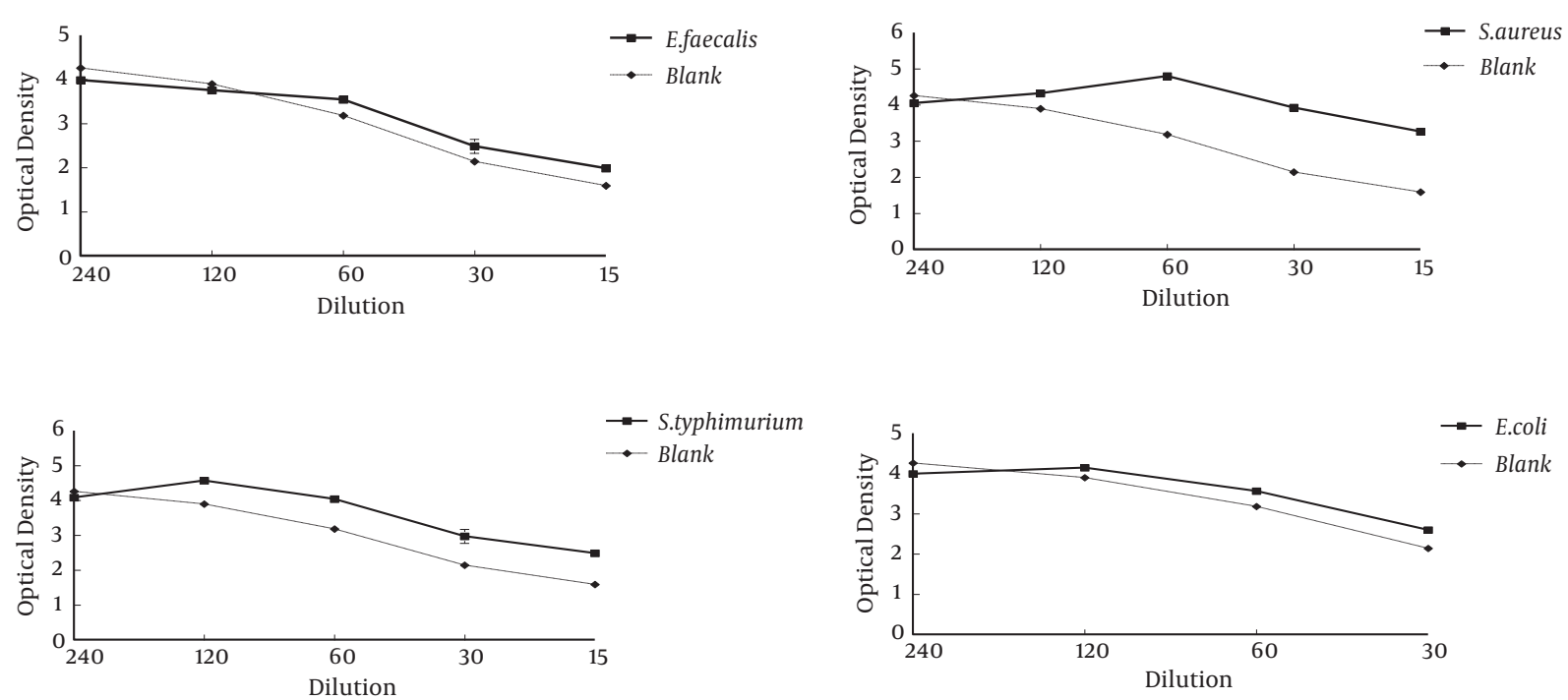

Figure 1. Antibacterial Effect of Aqueous Extract of Root of Salvia chorassanica on Tested Bacteria

method which is applied for extracting the active compounds. It seems that ethanolic and Hydro alcoholic extraction methods are more sufficient in extraction of active compounds and this can be related to extraction rates of these two methods. This means that the highest amount of extract is obtained using hydro alcoholic extraction method [18]. Researchers showed that the best solvent which is applied for obtaining raw extract from plant is ethanol or methanol $80 \%$. Since these mentioned solvents can solve and extract the $80 \%$ of active compounds from plants [7]. Different types of extracts of Salvia chorassanica root exhibited stronger inhibitory effect on the Grampositive bacteria than Gram-negatives bacteria. These results also supported by the study of Mosafa et al. (2014) [19] who investigated antimicrobial activity of ethanolic extract of salvia officinalis against Staphylococcus aureus, Escherichia coli, Pseudomonas aeruginosa and Klebsiella pneumoniae. They reported that ethanolic extract of salvia officinalis was more effective against Gram-positive bacteria than Gram-negative bacteria in vitro. The various ef- 

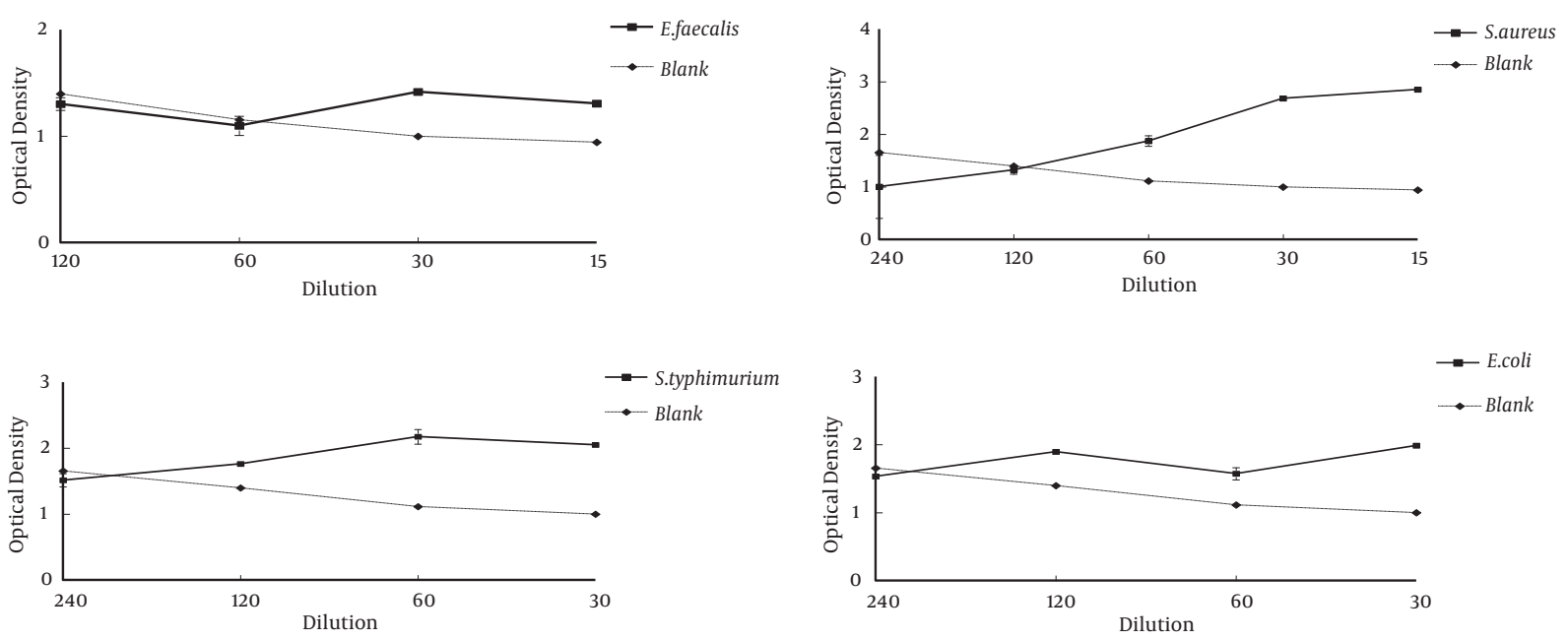

Figure 2. Antibacterial Effect of Ethanolic Extract of Root of Salvia chorassanica on Tested Bacteria
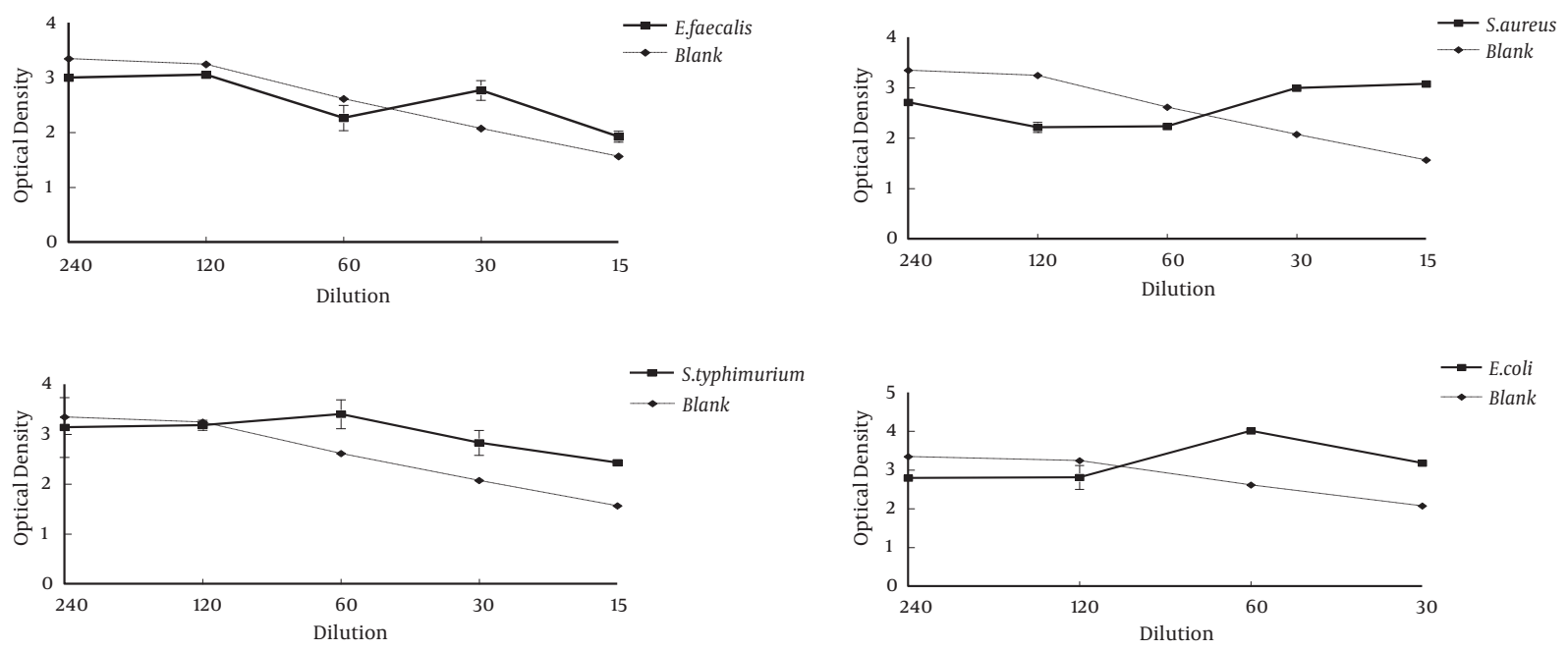

Figure 3. Antibacterial Effect of Hydro Alcoholic Extract of Root of Salvia chorassanica on Tested Bacteria

Table 2. Inhibition Zone of Common Therapeutic Antibiotics Against Tested Bacteria (Antibiogram Test)

\begin{tabular}{lcc}
\hline Antibiotic & Microorganism & Inhibition Zone, mm \\
\hline Chloramphenicol & E. faecalis & 16 \\
Tetracycline & S. aureus & 22 \\
Gentamicin & E. coli & 19 \\
Neomycin & S. typhimurium & 8 \\
\hline
\end{tabular}

fects of the extracts on Gram-positive and Gram-negative can be attributed to cell wall structure. Gram positive bacteria have more mucopeptide in their cell wall composition while gram negative bacteria possess only a thin layer of mucopeptide and most of their cell wall structure is composed of lipoprotein and lipopolysaccharides [20]. Different sensitivity between Gram-positive and negative bacteria can be related to morphological differences between these microorganisms. In Gram-negative bacteria with an outer phospholipidic membrane which is carrying the structural lipopolysaccharide components. This 
Table 3. Minimum Inhibitory Concentration (MIC) and Minimum Bactericidal Concentration (MBC) of Aqueous, Ethanolic and Hydro Alcoholic Extract of Salvia chorassanica Root on Staphylococcus aureus, Enterococcus faecalis, Salmonella typhimurium and Escherichia coli ${ }^{\mathrm{a}}$ b

\begin{tabular}{|c|c|c|c|}
\hline Type of Extract & Bacteria Species & MIC, $\mathbf{m g} / \mathbf{m L}$ & MBC, $\mathbf{m g} / \mathbf{m L}$ \\
\hline \multirow{4}{*}{ Aqueous } & S.aureus & $240 \pm 0.04^{C}$ & 480 \\
\hline & E.faecalis & $120 \pm 0.05^{\mathrm{B}}$ & 240 \\
\hline & S.typhimurium & $240 \pm 0.03^{C}$ & ND \\
\hline & E.coli & $240 \pm 0.03^{C}$ & 480 \\
\hline \multirow{4}{*}{ Ethanolic } & S.aureus & $120 \pm 0.08^{\mathrm{B}}$ & 240 \\
\hline & E.faecalis & $60 \pm 0.09^{A}$ & 120 \\
\hline & S.typhimurium & $240 \pm 0.10^{C}$ & ND \\
\hline & E.coli & $240 \pm 0.07^{\mathrm{C}}$ & ND \\
\hline \multirow{3}{*}{ Hydrialcoholic } & S.aureus & $60 \pm 0.02^{\mathrm{A}}$ & 120 \\
\hline & E.faecalis & $60 \pm 0.23^{A}$ & 120 \\
\hline & E.coli & $120 \pm 0.30^{\mathrm{B}}$ & 240 \\
\hline
\end{tabular}

Abbreviation: ND, not determent.

${ }^{a}$ Dissimilar capital letters indicate significant differences $(\mathrm{P}<0.05)$ of the antimicrobial effect of different extract.

${ }^{\mathrm{b}}$ Similar capital letters indicate the lack of significant differences $(\mathrm{P}<0.05)$ of the antimicrobial effect of different extract.

characteristics in the cell wall leads to impermeability to lipophilic solutes, while porins create a selective barrier to the hydrophilic solutes with an exclusion limit of about 600 Da [21].

The result of one-way ANOVA analysis revealed that increasing the concentration of the aqueous, ethanolic and hydro alcoholic extracts resulted in a significant growth in inhibition zone. There are significant differences among mean of all experiments so that we can attribute the presence or absence of these significant differences to the amount of active ingredients present in the extracts. In general, it can be said that effect of extract type, extract concentration and interaction between extract types and extract concentration for all tested bacteria in this study were statistically significant. Bhalodia and Shukla, 2011 [22] reported that antibacterial and antifungal activities of the hydro alcohol extracts of leaves of Cassia fistula Linn against two Gram-positive-Staphylococcus aureus, Streptococcus pyogenes-two Gram-negative-Escherichia coli, Pseudomonas aeruginosa human pathogenic bacteria-and three fungal strains-Aspergillus niger, Aspergillus clavatus, Candida albicans-increased linearly with growing in concentration of extracts $(\mu \mathrm{g} / \mathrm{mL})$. This result is consistent with the findings of this study.

This study determined that the ethanolic and hydro alcoholic extracts compared to the aqueous extract was more effective and had greater inhibitory effect. Heidari Sureshjani et al. 2015 [17] also showed that ethanolic extract of Salvia chorassanica had exhibited broad spectrum activity against Enterobacter aerogenes, Listeria innocua and Bacillus subtilis as compared to aqueous extract. Previous chemical investigations on different species of salvia have shown the presence of flavonoids, diterpenoids, triterpenoids, sesterterpenes, and essential oils exhibits the antitumor, antimicrobial, cytotoxic and anti-inflammatory activities [23-25].

Alizadeh Behbahani et al. 2015 investigated the antibacterial effects of aqueous and ethanolic Avicenna marina extracts on Alternaria citri and Penicillium digitatum. In Alizadeh Behbahani et al.'s study [26] the aqueous and ethanolic extracts were showed more inhibition zone with increasing concentration against Alternaria citri and Penicillium digitatum.

The result of this study suggest that extract of Salvia chorassanica have considerable antimicrobial ability against the studied strains "in vitro", which can be used as an alternative for antibiotics. The inhibition of growth of tested bacteria, that are known as pathogens, and displaying multidrug resistant to antibiotics agents, legitimize the continued application of this plant in public and traditional medical practice. Therefore, pharmacological test is necessary to isolate and characterize their active compounds. In addition, more studies should be done "in Situ" and "in vivo", in order to identify the effective dose of the extract on the microorganisms and better understand their safety, efficacy and properties. 


\section{Acknowledgments}

The authors wish to thank and appreciate research's deputy of Ferdowsi University of Mashhad for providing the expenditure of this project and help to performance of this project with the code 31743 which adopted at $102^{\text {th }}$ meeting of the research council of agricultural faculty.

\section{Footnotes}

Authors' Contribution: All authors had equal role in design, work, statistical analysis and manuscript writing.

Funding/Support: This research study was financially supported by Ferdowsi University of Mashhad.

\section{References}

1. Hammer KA, Carson CF, Riley TV. Antimicrobial activity of essential oils and other plant extracts. J Appl Microbiol. 1999;86(6):985-90. [PubMed: 10438227].

2. Dorman HJ, Deans SG. Antimicrobial agents from plants: antibacterial activity of plant volatile oils. J Appl Microbiol. 2000;88(2):308-16. [PubMed: 10736000].

3. Nascimento G, Locatelli J, Freitas P, Silva G. Antibacterial activity of plant extract and phytochemical on antibiotic resistant bacteria. Brazilian J of Microbiol. 2000;31:247-56. doi: 10.1590/S151783822000000400003.

4. Fankam AG, Kuete V, Voukeng IK, Kuiate JR, Pages JM. Antibacterial activities of selected Cameroonian spices and their synergistic effects with antibiotics against multidrug-resistant phenotypes. BMC Complement Altern Med. 2011;11:104. doi: 10.1186/1472-6882-11-104. [PubMed: 22044718].

5. Tayarani-Najaran Z, Asili J, Aioubi E, Emami SA. Growth Inhibition and Apoptosis Induction of Salvia chloroleuca on MCF-7 Breast Cancer Cell Line. Iran J Pharm Res. 2013;12(4):789-99. [PubMed: 24523759].

6. Gohari AR, Ebrahimi H, Saeidnia S, Foruzani M, Ebrahimi P, Ajani Y. Flavones and Flavone Glycosides from Salvia macrosiphon Boiss. Iran J Pharm Res. 2011;10(2):247-51. [PubMed: 24250350].

7. Samsam Shariat H. Extraction of effective components from medicinal plants and their diagnostic and evaluation methods. Iran: Isfahan: Mani Press; 1992.

8. Ahmad I, Beg AZ. Antimicrobial and phytochemical studies on 45 Indian medicinal plants against multi-drug resistant human pathogens. J Ethnopharmacol. 2001;74(2):113-23. [PubMed: 11167029].

9. Valero M, Salmeron MC. Antibacterial activity of 11 essential oils against Bacillus cereus in tyndallized carrot broth. Int J Food Microbiol. 2003;85(1-2):73-81. [PubMed: 12810272].

10. Awoyinka OA, Balogun IO, Ogunnowo AA. Phytochemical screening and in vitro bioactivity of Cnidoscolus aconitifolius (Euphorbiaceae) J Med Pl Res. 2007;1(3):63-5. doi: 10.4103/0974-8490.138290.
11. Gulluce M, Sahin F, Sokmen M, Ozer H, Daferera D, Sokmen A, et al. Antimicrobial and antioxidant properties of the essential oil and methanol extract from Mentha Longifolia 1. spp.longifolia. Food Chem. 2007;103:1449-56. doi:10.1016/j.foodchem.2006.10.061.

12. Ozturk S, Ercisli S. Antibacterial activity and chemical constitutions of Ziziphora clinopodioide. Food Cont. 2007;18(5):535-40. doi: 10.1016/j.foodcont.2006.01.002.

13. Duffy CF, Power RF. Antioxidant and antimicrobial properties of some Chinese plant extracts. Int J Antimicrob Agents. 2001;17(6):527-9. [PubMed: 11434342].

14. Ababutain IM. Antimicrobial Activity of Ethanolic Extracts from Some Medicinal Plant. Australian J of Bas and App Sci. 2011;5(11):678-83.

15. Al-Mariri A, Safi M. In Vitro Antibacterial Activity of Several Plant Extracts and Oils against Some Gram-Negative Bacteria. Iran J Med Sci. 2014;39(1):36-43. [PubMed: 24453392].

16. Neves JM, Matos C, Moutinho C, Queiroz G, Gomes LR. Ethnopharmacological notes about ancient uses of medicinal plants in Tras-osMontes (northern of Portugal).JEthnopharmacol. 2009;124(2):270-83. doi: 10.1016/j.jep.2009.04.041. [PubMed: 19409473].

17. Heidari-Sureshjani M, Tabatabaei-Yazdi F, Alizadeh-Behbahani B, Mortazavi A. Antimicrobial effect of aqueous and ethanolic extracts of Satureja bachtiarica on some pathogenic bacteria in vitro. Zahedan J Res Med Sci. 2015;17(7):25-9. doi:10.17795/zjrms1017.

18. Nostro A, Germano MP, D’Angelo V, Marino A, Cannatelli MA. Extraction methods and bioautography for evaluation of medicinal plant antimicrobial activity. Lett Appl Microbiol. 2000;30(5):379-84. [PubMed: 10792667].

19. Mosafa E, Yahyaabadi S, Doudi M. In vitro antibacterial properties of sage (Salvia officinalis) ethanol extracts against multidrug resistant staphylococcus aureus, escherichia coli, pseudomonas aeruginosa and klebsiella pneumoniae. Zahedan J Res Med Sci. 2014;16(10):42-6.

20. Palombo EA, Semple SJ. Antibacterial activity of traditional Australian medicinal plants. J Ethnopharmacol. 2001;77(2-3):151-7. [PubMed: 11535358].

21. Nikaido H, Vaara M. Molecular basis of bacterial outer membrane permeability. Microbiol Rev. 1985;49(1):1-32. [PubMed: 2580220].

22. Bhalodia NR, Shukla VJ. Antibacterial and antifungal activities from leaf extracts of Cassia fistula l.: An ethnomedicinal plant. J Adv Pharm Technol Res. 2011;2(2):104-9. doi: 10.4103/2231-4040.82956. [PubMed: 22171301].

23. Wang M, Kikuzaki H, Zhu N, Sang S, Nakatani N, Ho CT. Isolation and structural elucidation of two new glycosides from sage (Salvia officinalis L.). J Agric Food Chem. 2000;48(2):235-8. [PubMed: 10691621].

24. Lu Y, Foo LY. Polyphenolics of Salvia-a review. Phytochemistry. 2002;59(2):117-40. [PubMed: 11809447].

25. Ayatollahi SA, Shojaiia A, Kobarfard F, Mohammadzadehd M, Choudharye MI. Two Flavones from Salvia leriaefolia. Iran J Pharm Res. 2009;8(3):179-84

26. Alizadeh-Behbahani B, Tabatabaei-Yazdi F, Shahidi F, Riazi F. Antifungal effect of the aqueous and ethanolic Avicennia marina extracts on Alternaria citri and Penicillium digitatum. Zahedan J Res Med Sci. 2015;inpress(inpress). 